\title{
A 7-fold interpenetrated 3D porous coordination polymer (PCP) with nitrobenzene sensing properties
}

Peng Wang, ${ }^{\mathrm{a}, \mathrm{b}} \mathrm{Ji} \mathrm{Xu},{ }^{\mathrm{a}}$ Qi-Dong Zhuo, ${ }^{\mathrm{a}, \mathrm{b}}$ Yun-Sheng Ma, ${ }^{\mathrm{a}}$ Hong-Jian Cheng, ${ }^{\mathrm{a}}$ Xiao-Yan Tang, ${ }^{\text {a }}$ Rong-Xin Yuan ${ }^{\mathrm{a}}$

${ }^{a}$ School of Chemistry and Materials Engineering, Changshu Institute of Technology, Changshu, Jiangsu 215500, China

${ }^{b}$ School of Chemical Engineering and Technology, China University of Mining and Technology, Xuzhou, Jiangsu 221000, China

\begin{abstract}
A $\mathrm{Zn}(\mathrm{II})$-based porous coordination polymer (PCP) $\left\{\left[\mathrm{Zn}_{2}(\mathrm{ppt})_{2}(\mathrm{fdc})\left(\mathrm{H}_{2} \mathrm{O}\right)_{2}\right] \cdot 2 \mathrm{DMF}\right\}_{\mathrm{n}}(\mathbf{1})\left(\mathrm{H}_{2} \mathrm{fdc}=\right.$ 9H-fluorene-2,7-dicarboxylic acid, Hppt = 3-(2-pyrazinyl)-5-(4-pyridyl)-1,2,4-triazole) has been synthesized under hydrothermal conditions. The resulting PCP shows a 7-fold interpenetrated 3D structure that can be simplified as a diamond-like structure with $\mathrm{Zn} 1$ as node and $\mathrm{fdc}^{-}$and $\mathrm{Zn}(\mathrm{ppt})_{2}$ as spacers. It exhibits strong luminescence at room temperature in solid-state. Luminescent property study shows that $\mathbf{1}$ can be used as a fluorescent sensor for nitrobenzene (NB).
\end{abstract}

Keywords: zinc coordination polymer; 7-fold interpenetrated; fluorescence; nitrobenzene sensing

* Corresponding authors. Tel.: +86 51252251173.

E-mail: myschem@hotmail.com (Y.-S. Ma), yuanrx@cslg.edu.cn (R.-X. Yuan). 
Nitrobenzene (NB) is widely used as an important raw material in plastic processing, chemical synthesis of pesticides and the production of aniline ${ }^{[1,2]}$. Moreover, it is an important component of industrial explosives and it can be found in many mines all over the world. ${ }^{[3-5]}$ Due to its high toxicity and accumulation characteristics it could lead to serious environmental and security problems. So it is urgent to detect such toxicity substance. However, the traditional methods like gas chromatography-mass spectrometry (GC-MS), high performance liquid chromatography (HPLC) are used for detecting these substances still have many drawbacks such as expensive instrumentation, low portability and selectivity. ${ }^{[6]}$ It is still a challenge to gain novel luminescent sensors.

Porous coordination polymers (PCPs) also known as metal-organic frameworks (MOFs) have received considerable attention because of their potential applications in the fields such as photoluminescence, gas storage/separation, magnetic properties, sensor and catalysis. ${ }^{[7-12]}$ Among these applications, the luminescent properties of MOFs have attracted attention for a long time. Recently, Ma et al. reported a novel $\mathrm{Zn}-\mathrm{MOF} \quad\left[\mathrm{Zn}_{3}(\mathrm{TDPAT})\left(\mathrm{H}_{2} \mathrm{O}\right)_{3}\right] \quad[\mathrm{TDPAT}=$ 2,4,6-tris(3,5-dicarboxyl phenylamino)-1,3,5-triazine] with high luminescent intensity. After dispersed in different solvents, the compound shows highly selective sensor for $\mathrm{NB} \cdot{ }^{[13]}$ Liu et al. reported a porous luminescent Zn-MOF $\left[\mathrm{Zn}_{2}(\mathrm{TCPPE})\right]\left\{\mathrm{H}_{4} \mathrm{TCPPE}=\right.$ tetrakis[4-(4-carboxyphenyl)phenyl]ethane $\}$ with highly fluorescence quenching effect towards NB. ${ }^{[1]}$ Thus the luminescent MOFs are ideal sensors for NB.

The suitable ligand is important to build a luminescent PCP. We noticed that fluorene has large $\pi$ conjugation system and always shows strong fluorescent intensity. Moreover, it is easy to introduce functional group at the aromatic 2,7-positions. ${ }^{[15]}$ In this paper, we use the 9 H-fluorene-2,7-dicarboxylic acid $\left(\mathrm{H}_{2} \mathrm{fdc}\right)^{[16]}$ to construct a Zn-based luminescent PCP with the support of 3-(pyridine-4-yl)-5-(pyradin-2-yl)-1H-1,2,4-triazole $(\mathrm{Hppt})^{[17]}$. In the present work, compound $\left\{\left[\mathrm{Zn}_{2}(\mathrm{ppt})_{2}(\mathrm{fdc})\left(\mathrm{H}_{2} \mathrm{O}\right)_{2}\right] \cdot 2 \mathrm{DMF}\right\}_{\mathrm{n}}(\mathbf{1})$ was obtained under hydrothermal conditions. It has a 7-fold interpenetrated 3D structure. This interpenetrating phenomenon can be observed frequently in the self-assembling system. ${ }^{[18,19]}$ The luminescent and sensing properties of compound $\mathbf{1}$ were studied at room temperature. 
Compound 1 was prepared by mixing $\mathrm{H}_{2} \mathrm{fdc}$, Hppt, $\mathrm{Zn}\left(\mathrm{NO}_{3}\right)_{2} \cdot 6 \mathrm{H}_{2} \mathrm{O}$ in a $\mathrm{H}_{2} \mathrm{O} / \mathrm{DMF}$ solution in a 6 $\mathrm{mL}$ sealed glass-tube under hydrothermal conditions. ${ }^{[20]}$ It is found that temperature and molar ratio are important for the formation of the pure product. When the temperature was raised to $120{ }^{\circ} \mathrm{C}$, an unknown light yellow precipitate was formed that was not characterized. Increasing in the content of $\mathrm{H}_{2} \mathrm{fdc}\left[\mathrm{H}_{2} \mathrm{fdc}: \mathrm{Hppt}: \mathrm{Zn}\left(\mathrm{NO}_{3}\right)_{2} \cdot 6 \mathrm{H}_{2} \mathrm{O}=2: 1: 4\right]$ or reduction of $\mathrm{H}_{2} \mathrm{fdc}\left[\mathrm{H}_{2} \mathrm{fdc}: \mathrm{Hppt}: \mathrm{Zn}\left(\mathrm{NO}_{3}\right)_{2} \cdot 6 \mathrm{H}_{2} \mathrm{O}=1: 2: 4\right]$ will lead to the formation of the uncharacterized white precipitate.

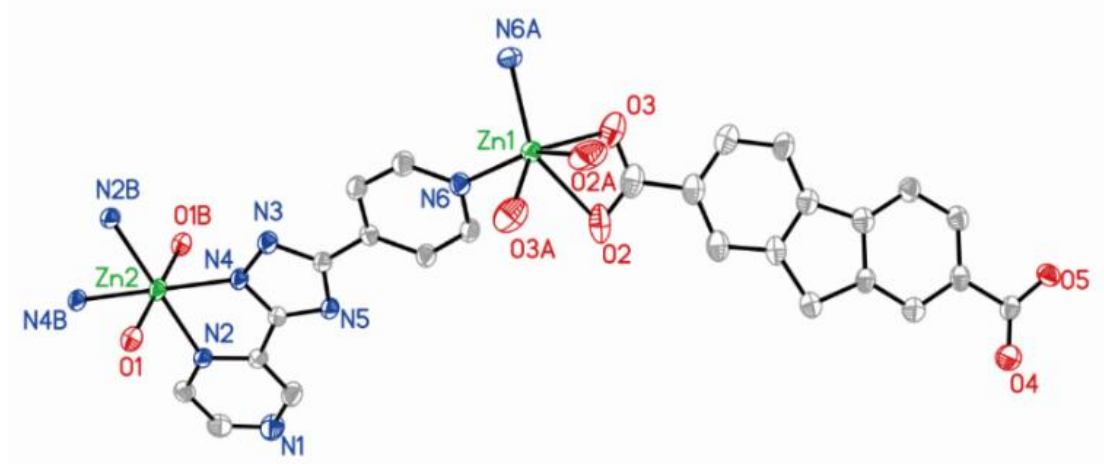

Figure 1 View of the coordination environments of $\mathrm{Zn}(\mathrm{II})$ ions in compound $\mathbf{1 .}$

Symmetry codes: A: 1-x, y, 3/2-z; B: 1-x, -1+y, 1/2-z.

Single crystal X-ray diffraction analysis reveals that compound $\mathbf{1}$ has a 7-fold 3D interpenetrated framework that crystallizes in the monoclinic space group $\mathrm{C} 2 / \mathrm{c} .{ }^{[21]}$ The asymmetric unit consists of two distinct zinc atoms with each has 0.5 occupation, one $\mathrm{ppt}^{-}$, half a fdc ${ }^{2-}$ ligand and one coordinated water (Figure 1). Both $\mathrm{Zn} 1$ and $\mathrm{Zn} 2$ are six-coordinated in an octahedral geometry. Zn1 is coordinated by four oxygen atoms (O2, O3, O2A, O3A.) from two equivalent $\mathrm{fdc}^{2-}$ ligands and two nitrogen atoms (N6 and N6A) from two $\mathrm{ppt}^{-}$anions. $\mathrm{Zn} 2$ is coordinated by four nitrogen atoms (N2, N4, N2B, N4B) from two ppt $^{-}$anions and two oxygen atoms (O1 and O1B) from two coordinated water molecules. The $\mathrm{Zn}-\mathrm{O}$ and Zn-N bond lengths are in the range of 2.105(7)-2.397(7) $\AA$ and 2.035(2)-2.192(3) A, respectively, which are comparable to $\left[\mathrm{Zn}_{4}(\mathrm{Hbpvp})_{2}(\mathrm{BTC})_{3}(\mathrm{HCOO})\left(\mathrm{H}_{2} \mathrm{O}\right)_{2}\right] \cdot 4 \mathrm{H}_{2} \mathrm{O} \quad[\mathrm{Zn}-\mathrm{O}: 2.005(3)-2.276(3)$; bpvp = 3,5-bis-(2-(pyridin-4-yl)vinyl)pyridine; $\quad \mathrm{H}_{3}$ BTC $=1,3,5$-benzenetricarboxylic $\quad$ acid $]^{[22]}$ and $\left\{\left[\mathrm{Zn}_{2}(\mathrm{TZI})(\mathrm{OH})\left(\mathrm{H}_{2} \mathrm{O}\right)_{2}\right]\left(\mathrm{H}_{2} \mathrm{O}\right)\right\}_{n} \quad\left[\mathrm{Zn}-\mathrm{N}:\right.$ 2.018(4)-2.138(4); $\mathrm{H}_{3} \mathrm{TZI}=$ 5-(1H-tetrazol-5-yl)isophthalic acid]. ${ }^{[23]}$ The Zn1 atoms were bridged by two carboxylate groups into a zigzag chain along the c-axis. 
These chains are connected by $\mathrm{Zn}(\mathrm{ppt})_{2}$ into a 3D network with large pores. From a topological point of view, the $3 \mathrm{D}$ architecture can be treated as a $6^{6}$ diamondoid network with $\mathrm{Zn} 1$ as node and fdc and $\mathrm{Zn}(\mathrm{ppt})_{2}$ as spacers. ${ }^{[24]}$ Although the single $3 \mathrm{D}$ net has a large pore size, its void space is interpenetrated by other six independent 3D frameworks, resulting in the 7-fold interpenetrated structure (Figure S1). The potential void in each unit cell is $1042.7 \AA^{3}$ (24.1\% of the unit cell volume).

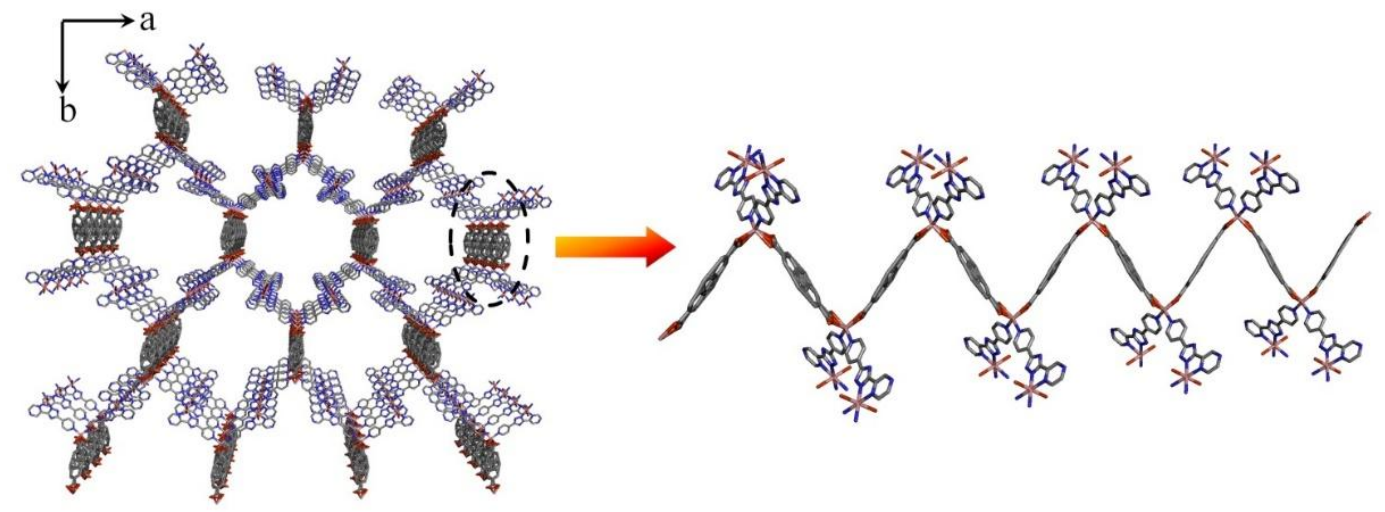

Figure 2 View of the 3D framework for compound $\mathbf{1}$ along the c-axis.

The experimental powder X-ray diffraction (PXRD) patterns are in good agreement with the simulated ones, indicating the obtained crystal materials are identical (Figure S2). In different organic solvents compound $\mathbf{1}$ could maintain its crystalline, confirming the stability of compound $\mathbf{1}$ Thermogravimetric analysis shows a weight loss $(19.5 \%)$ in the temperature range $50-250{ }^{\circ} \mathrm{C}$, in agreement with the calculated value of $18.0 \%$ for the removal of two guest DMF and two coordinated water molecules (Figure S3).

The luminescent properties for compound $\mathbf{1}$ as well as the free ligands were investigated in solid-state at room temperature. As shown in Figure 3a, the emission peaks of the free ligands Hppt and $\mathrm{H}_{2}$ fdc display fluorescent emission band at $543 \mathrm{~nm}$ and $425 \mathrm{~nm}$, respectively. In comparison, compound 1 shows an emission peak at $466 \mathrm{~nm}$ with fluorescent intensity of 6912, which is stronger than that for $\mathrm{H}_{2} \mathrm{fdc}$ (429) and Hppt (979). The fluorescent enhancement in compound $\mathbf{1}$ can partly attribute to the formation of the 3-D structure, which has enabled the rigidity. In addition, the $\pi \cdots \pi$ stacking interactions (the closest distance between the aryl planes is $3.527 \AA$ ) in compound $\mathbf{1}$ also contribute to the enhancement of fluorescence. ${ }^{[25]}$ The high fluorescent intensity makes it possible to sense small 
molecules.
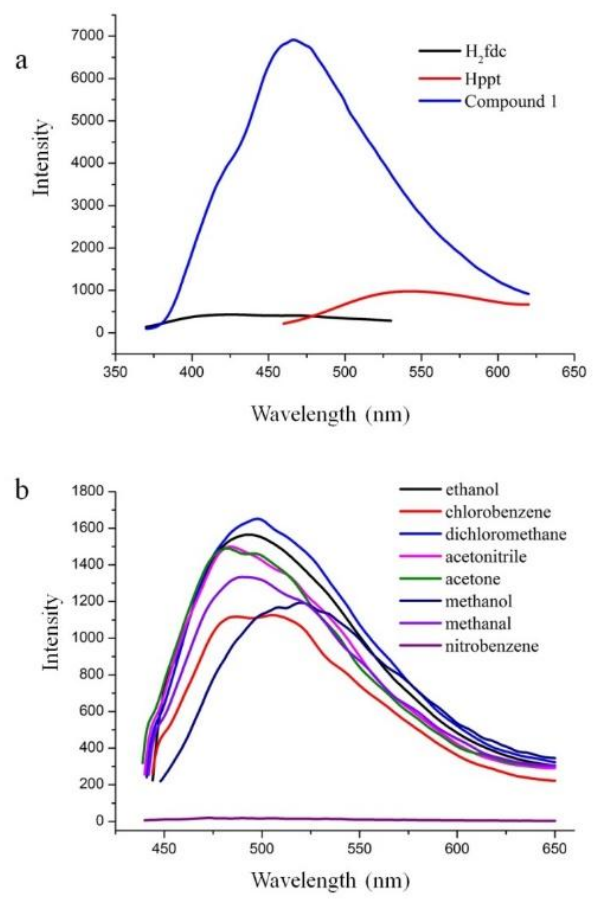

Figure 3 (a) The emission spectra for compound $1(\lambda e x=354 \mathrm{~nm})$, Hppt $(\lambda e x=318 \mathrm{~nm})$ and $\mathrm{H}_{2} \mathrm{fdc}(\lambda \mathrm{ex}=375 \mathrm{~nm})$.

(b) Emission spectra of compound $\mathbf{1}$ dispersed in different solvents ( $\lambda \mathrm{ex}=419 \mathrm{~nm})$.

The luminescent properties of compound $\mathbf{1}$ dispersed in different solvents such as ethanol, chlorobenzene, dichloromethane, acetonitrile, acetone, methanol, ethanol and nitrobenzene have been studied systematically. As shown in Figure 3b, the maximum emission peaks show an obvious red-shift in organic solvents except nitrobenzene. This red-shift is attribute to the solvatochromatic effect. ${ }^{[26,27]}$ Interestingly, the fluorescence of compound $\mathbf{1}$ disappeared in nitrobenzene solution. This is the typical fluorescent quenching phenomena, which may be due to the electron transfer from the benzene groups of $\mathrm{H}_{2} \mathrm{fdc}$ and Hppt ligands to nitrobenzene. ${ }^{[28-30]}$ Thus, compound $\mathbf{1}$ could be used as a probe for sensing nitrobenzene.

In summary, we synthesized a 7-fold interpenetrated luminescent PCP with $\mathrm{H}_{2} \mathrm{fdc}$ and $\mathrm{Hppt}$ as ligands. It displays high fluorescence intensity and shows highly sensing property on nitrobenzene. This work reveals that the using of potential fluorescent ligand such as $\mathrm{H}_{2} \mathrm{fdc}$ could form typical PCP for sensing of toxic chemical molecules. Further work is in progress to study the sensing properties for toxic metal ions. 


\section{Acknowledgements}

This work is supported by NSF of Jiangsu Provence (Nos. 14KJA150001, 14KJB150001). The Six Talent Peaks project in Jiangsu Province.

\section{Appendix A. Supplementary data}

CCDC 1445023 contains the supplementary crystallographic data for $\mathbf{1}$. The data can be obtained free of charge from the Cambridge Crystallographic Data Centre, 12 Union Road, Cambridge CB21EZ, UK; fax: (+44) 1223-336-033; or e-mail: deposit@ccdc.cam.ac.uk. Supplementary data containing Table S1, Figures S1, S2, S3 and S4 to this article can be found online at

\section{References}

[1] H.K. Zhang, S.X. Liang, S.J. Liu, Determination of nitrobenzene by differential pulse voltammetry and its application in wastewater analysis, Anal. Bioanal. Chem. 387 (2007) 1511-1516.

[2] J. Wang, H. Lu, Y. Zhou, Y. Song, G. Liu, Y. Feng, Enhanced biotransformation of nitrobenzene by the synergies of shewanella species and mediator-functionalized polyurethane foam, J. Hazard. Mater. 252 (2013) 227-232.

[3] X.C. Sun, Y. Wang, Y. Lei, Fluorescence based explosive detection: from mechanisms to sensory materials, Chem. Soc. Rev. 44 (2015) 8019-8061.

[4] S. Pramanik, C. Zheng, X. Zhang, T. J. Emge, J. Li, New microporous metal-organic framework demonstrating unique selectivity for detection of high explosives and aromatic compounds, J. Am. Chem. Soc. 133 (2011) 4153-4155.

[5] M.E. Germain, M.J. Knapp, Optical explosives detection: from color changes to fluorescence turn-on, Chem. Soc. Rev. 38 (2009) 2543-2555.

[6] D.S. Moore, Instrumentation for trace detection of high explosives, Rev. Sci. Instrum. 75 (2004) 2499-2512.

[7] Y.J. Cui, Y.F. Yue, G.D. Qian, B.L. Chen, Luminescent functional metal-organic frameworks, 
Chem. Rev. 112 (2012) 1126-1162.

[8] D.Y. Hong, C. Serre, G. Ferey, J.S. Chang, Porous chromium terephthalate MIL - 101 with coordinatively unsaturated sites: surface functionalization, encapsulation, sorption and catalysis, Adv. Funct. Mater. 19 (2009) 1537-1552.

[9] P. Horcajada, T. Chalati, C. Serre, B. Gillet, C. Sebrie, T. Baati, J.F. Eubank, D. Heurtaux, Porous metal-organic-framework nanoscale carriers as a potential platform for drug delivery and imaging, Nature Mater. 9 (2010) 172-178.

[10] H.H. Zou, Y.P. He, L.C. Gui, F.P. Liang, A new 8-connected porous coordination polymer: crystal structure and selective adsorption properties, CrystEngComm. 113 (2011) 3325-3329.

[11] L. Zhou, C. Wang, X. Zheng, Z. Tian, L. Wen, H. Qu, D. Li, New metal-organic frameworks based on 2,5-thiophenedicarboxylate and pyridine-or imidazole-based spacers: syntheses, topological structures, and properties, Dalton Trans. 42 (2013) 16375-16386.

[12] L. Qin, M.X. Zheng, Z.J. Guo, H.G. Zheng, Y. Xu, One non-interpenetrated chiral porous multifunctional metal-organic framework and its applications for sensing small solvent molecules and adsorption, Chem. Commun. 51 (2015) 2447-2449.

[13] D.X Ma, B.Y. Li, X.J. Zhou, Q. Zhou, K. Liu, G. Zeng, G.H. Li, S.H. Feng, A dual functional MOF as a luminescent sensor for quantitatively detecting the concentration of nitrobenzene and temperature, Chem. Commun. 49 (2013) 8964-8966.

[14] X.G. Liu, H. Wang, B. Chen, Y. Zou, Z. G. Gu, Z. J. Zhao, L. Shen, A luminescent metal-organic framework constructed using a tetraphenylethene-based ligand for sensing volatile organic compounds, Chem. Commun. 51 ( 2015) 1677-1680.

[15] M.P. Aldred, C. Li, G.F. Zhang, W.L. Gong, Y.F. Dai, D.G. Ma, M.Q. Zhu, Fluorescence quenching and enhancement of vitrifiable oligofluorenes end-capped with tetraphenylethene, J. Mater. Chem. 22 (2012) 7515-7528.

[16] P.J. Skabara, S. Rory Berridge, I.M. Serebryakov, S. Christoph Winder, Fluorene functionalised sexithiophenes - utilising intramolecular charge transfer to extend the photocurrent spectrum in organic 
solar cells, J. Mater. Chem. 17 (2007) 1055-1062.

[17] K.S. Yeung, M.E. Farkas, J.F. Kadow, A base-catalyzed, direct synthesis of 3, 5-disubstituted 1,2,4-triazoles from nitriles and hydrazides, Tetrahedron letters. 46 (2005) 3429-3432.

[18] G.P. Yang, L. Hou, L.F. Ma,Y.Y. Wang, Investigation on the prime factors influencing the formation of entangled metal-organic frameworks, CrystEngComm. 15 (2013) 2561-2578.

[19] G.P. Yang, L. Hou, X.J Luan, B. Wu, Y.Y. Wang, Molecular braids in metal-organic frameworks, Chem. Soc. Rev. 41 (2012) 6992-7000.

[20] A mixture of $\mathrm{Zn}\left(\mathrm{NO}_{3}\right)_{2} \cdot 6 \mathrm{H}_{2} \mathrm{O}(12 \mathrm{mg}, 0.04 \mathrm{mmol})$, Hppt (4.48 mg, $\left.0.02 \mathrm{mmol}\right), \mathrm{H}_{2} \mathrm{fdc}(5.04 \mathrm{mg}$, $0.02 \mathrm{mmol}$ ), $0.5 \mathrm{~mL}$ of $\mathrm{H}_{2} \mathrm{O}$ and $1.5 \mathrm{~mL}$ of DMF were sealed in a $6 \mathrm{~mL}$ glass-tube and heated at $90{ }^{\circ} \mathrm{C}$ for 2 days. Pale yellow crystals were obtained after the mixture was cooled to room temperature (Yield: $36 \%$, based on Hppt). Anal. calcd for $\mathrm{C}_{43} \mathrm{H}_{40} \mathrm{~N}_{14} \mathrm{O}_{8} \mathrm{Zn}_{2}:$ C, 51.05; H, 3.99; N, 19.38. Found: C, 50.84; $\mathrm{H}$, 3.92; N, 19.11\%. IR $\left(\mathrm{KBr}, \mathrm{cm}^{-1}\right): 3411.7 \mathrm{~cm}^{-1}(\mathrm{~s}), 1655.6 \mathrm{~cm}^{-1}(\mathrm{~s}), 1618.6 \mathrm{~cm}^{-1}(\mathrm{~s}), 1437.1 \mathrm{~cm}^{-1}(\mathrm{~m})$, $1385.9 \mathrm{~cm}^{-1}(\mathrm{~m}), 1325.5 \mathrm{~cm}^{-1}(\mathrm{~m}), 1187.5 \mathrm{~cm}^{-1}(\mathrm{w}), 1061.0 \mathrm{~cm}^{-1}(\mathrm{w}), 771.2 \mathrm{~cm}^{-1}(\mathrm{w}), 716.4 \mathrm{~cm}^{-1}(\mathrm{w})$.

[21] Single crystal X-ray diffraction data for compound 1 was carried out on a Bruker APEX-II CCD diffractometer with graphite-monochromated Mo $\mathrm{K} \alpha$ radiation $(\lambda=0.71073 \AA)$ at room temperature. The structure was solved with direct method and refined with the full-matrix least-square method on $\mathrm{F}^{2}$ using SHELXL. ${ }^{[31]}$ All of the non-hydrogen atoms were refined anisotropically. All the H atoms were refined isotropically, with the isotropic vibration parameters related to the non- $\mathrm{H}$ atom to which they are bonded. Crystallographic data for compound 1: $\mathrm{C}_{43} \mathrm{H}_{40} \mathrm{~N}_{14} \mathrm{O}_{8} \mathrm{Zn}_{2}, M r=1011.67$, monoclinic, space group $C 2 / \mathrm{c}, a=33.619 \AA, b=7.0530 \AA, c=20.347 \AA, \alpha=90.00^{\circ}, \beta=116.04^{\circ}, \gamma=90.00^{\circ}, V=$ $4334.8 \AA^{3}, Z=4, D c=1.550 \mathrm{~g} / \mathrm{cm}^{3}, F(000)=2080.0, \mathrm{GOF}=1.093, \mu=1.179 \mathrm{~mm}^{-1}, R($ int $)=0.0256$, final $\mathrm{R}$ indices $[I>2 \sigma(I)] R_{1}=0.0323$ and $w R_{2}=0.0873$.

[22] Y.X. Shi, F.L. Hu, W.H. Zhang, J.P. Lang, A unique Zn(II)-based MOF fluorescent probe for the dual detection of nitroaromatics and ketones in water, CrystEngComm. 17 (2015) 9404-9412 
[23] A.J. Calahorro, A. Salinas-Castillo, J.M. Seco, Luminescence and magnetic properties of three metal-organic frameworks based on the 5-(1H-tetrazol-5-yl) isophthalic acid ligand, CrystEngComm. 15 (2013) 7636-7639.

[24] D. Liu, Y.J. Chang, J.P. Lang, Ligand geometry-driven formation of different coordination polymers from $\mathrm{Zn}\left(\mathrm{NO}_{3}\right)_{2}$, 1,4-bpeb and phenylenediacetic acids, CrystEngComm. 13 (2011) 1851-1857. [25] C. Janiak, A critical account on $\pi-\pi$ stacking in metal complexes with aromatic nitrogen-containing ligands, Dalton Trans. 21 (2000) 3885-3896.

[26] S. Nigam, S.C. Rutan, Principles and applications of solvatochromism, Applied Spectroscopy. 55(2001) 362A-362A.

[27] Z. Lu, L. Wen, Z. Ni, Syntheses, structures, and photoluminescent and magnetic studies of metal-organic frameworks assembled with 5-sulfosalicylic acid and 1,4-bis (imidazol-1-ylmethyl)-benzene, Cryst. Growth Des. 7(2007) 268-274.

[28] D. Ma, B. Li, X. Zhou, A dual functional MOF as a luminescent sensor for quantitatively detecting the concentration of nitrobenzene and temperature, Chem. Commun. 49 (2013) 8964-8966.

[29] G.Y. Wang, C. Song, D.M. Kong, W.J. Ruan, Z. Chang, Y. Li, Two luminescent metal-organic frameworks for the sensing of nitroaromatic explosives and DNA strands, J. Mater. Chem. A. 2 (2014) 2213-2220.

[30] Y.L. Wu, G.P. Yang, Y.Q. Zhao, W.P. Wu, B. Liu, Y.Y. Wang, Three new solvent-directed Cd (II)-based MOFs with unique luminescent properties and highly selective sensors for $\mathrm{Cu}^{2+}$ cations and nitrobenzene, Dalton Trans. 44 (2015) 3271-3277.

[31] G.M. Sheldrick, A short history of SHELX, Acta Crystallogr. Sect. A: Fundam. Crystallogr. 64 (2008) 112-122. 

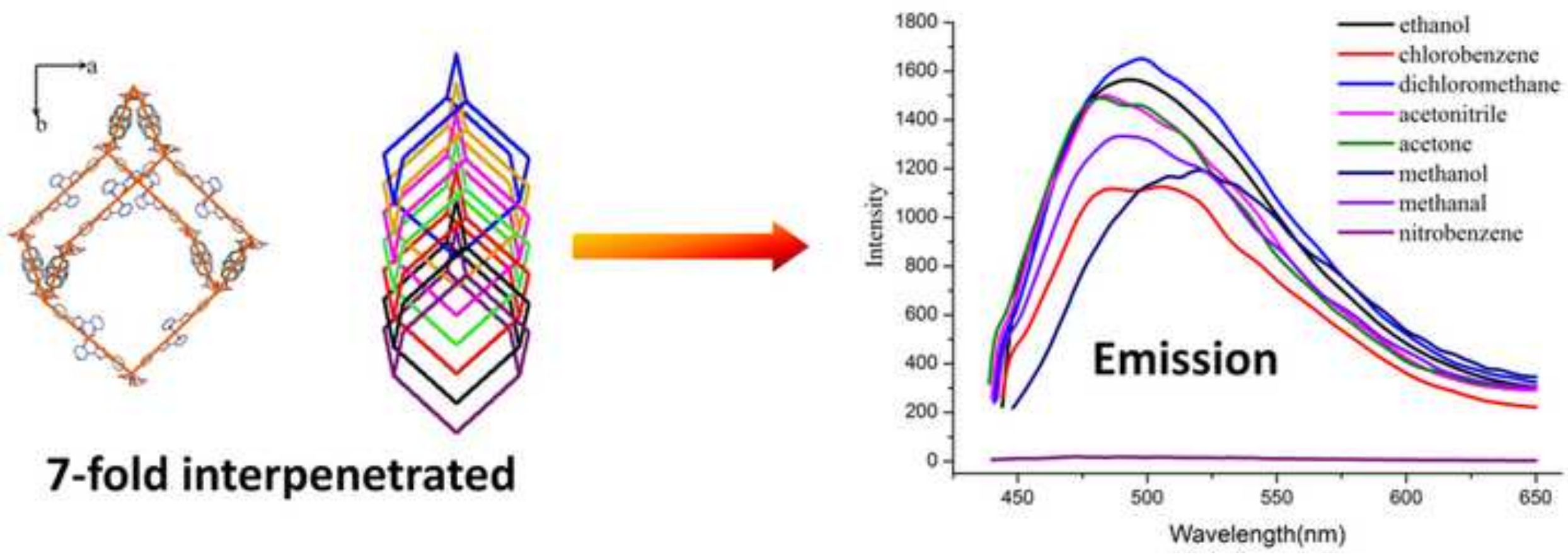

\section{7-fold interpenetrated}

$$
\text { Wavelength(nm) }
$$

